\title{
LOS INDOEUROPEOS Y EUROPA
}

\author{
Francisco Villar Liébana \\ Universidad de Salamanca
}

Nueve de las once lenguas más habladas en el mundo son indoeuropeas: inglés (480 millones), hindi (425), español (375), ruso (296), bengali (200), portugués (186), francés (125), alemán (122), lo que arroja 2.689 millones de hablantes. Podemos decir sin exagerar que uno de cada dos habitantes del planeta habla una lengua indoeuropea.

Geográficamente las lenguas indoeuropeas se extienden hoy por los cinco continentes: América (español, inglés, portugués), África (francés, holandés), Asia (hindi, bengali, etc.), Australia (inglés) y, sobre todo, Europa, donde la totalidad de las lenguas habladas actualmente son de la familia indoeuropea, con las minoritarias excepciones de húngaro, inhuit, finlandés y vasco.

En gran medida esa enorme proporción de hablantes y emplazamientos es el resultado de expansiones muy recientes (África, América, Australia). Antes de la Era de los Descubrimientos los indoeuropeos estaban circunscritos a Europa y Asia meridional. Una enorme extensión, de todas formas, que abarca desde las Islas Británicas hasta la India, en la que gentes indoeuropeas de diferentes variedades se encuentran asentadas firme y profundamente desde que existe memoria escrita de la historia.

Desde muy pronto, tras el descubrimiento de la conexión entre las lenguas indoeuropeas, se supuso que todas ellas procederian de la lengua de un pequeño pueblo originario, al que se ha dado en llamar indoeuropeo, que en un algún momento de la Prehistoria habría hablado una lengua común más o menos unitaria y habria estado asentado en un territorio más o menos pequeño desde el que se habria extendido por toda Europa y el Asia 
meridional. Los especialitas, casi sin excepción, tanto lingüistas como arqueólogos, han coincidido a lo largo de la historia de ambas ciencias en ese convencimiento básico. Pero no se ha logrado llegar a un acuerdo más allá de esa idea genérica. Los aspectos del problema que resultan ser cruciales para el conocimiento de la historia del Continente Europeo, por una parte, y la de los indoeuropeos, por otra, permanecen sin respuesta: cuál fue ese pueblo originario, dónde estuvo asentado, en qué época se habló esa lengua común, qué cultura de entre las prehistóricas fue la suya, en qué momento(s) y por qué vías se produjo su expansión desde ese reducto originario hasta la ocupación de casi toda Europa y el Asia meridional.

Ese conjunto de preguntas conforman lo que ha dado en llamarse el problema indoeuropeo. $\mathrm{Y}$ a su solución se han aplicado sucesivas generaciones de lingūistas y arqueólogos, cada uno de ellos armado con los instrumentos propios de sus respectivas disciplinas. El resultado de casi dos siglos de indagación arqueológica y lingüistica puede resumirse sin ambages en tres palabras: fracaso sin paliativos. No es que unos y otros no nos hayamos esforzado estrujándonos el ingenio en busca de argumentos; no es que no se haya derrochado ingenio, paciencia y trabajo. Todo eso se ha hecho en grandes dosis por parte de arqueólogos eximios y de indoeuropeistas de renombre. Pero todo ha sido en vano. Hoy, doscientos años después, seguimos sin conocer las respuestas a esas fundamentales preguntas.

Conatos de respuestas, pretendidas soluciones (es decir: teorías no demostradas) hay muchas y ha habido muchas más. Ninguna de ellas puede pretender a día de hoy ser la "verdadera" respuesta. Ninguna ha pasado de mera teoria para convertirse en verdad científica comprobada.

Pasaré por alto las mil y una ubicaciones en que se ha situado la patria originaria (Urheimat) desde el principio de la indagación y me limitaré a exponer las cuatro alternativas que hoy encontramos sobre el tapete, y que de hecho son defendidas actualmente por especialistas de uno u otro campo (lingüística y arqueología) o de ambos a la vez. 


\section{LAS TEORIAS EN LIZA}

\section{LA TEORIA TRADICIONAL}

El denominador común de todas las variantes en que se ha manifestado durante los últimos cien o ciento treinta anos la que aqui llamo teoría tradicional es que la patria originaria estuvo ubicada en el continente europeo. La primera de ellas' pretendia que hubiera sido en el Báltico, sobre la base de algunos argumentos de tipo racial: los indoeuropeos habrían sido rubios y el epicentro de la gente de cabellos rubios está en el Báltico.

Una segunda variante ${ }^{2}$ la situó en Escandinavia, con argumentos de varia índole. Por una parte utilizaba parecidos argumentos raciales: los indoeuropeos habrían sido rubios, como había señalado Poesche, pero dolicocéfalos, rasgos que se encuentran asociados en Escandinavia mejor que en los países Bälticos, donde predominarían los braquicéfalos. Otros argumentos eran de indole arqueológica: los indoeuropeos habrian sido sedentarios, agrícolas, lo que exigiría un territorio con posibilidades para la agricultura y, en opinión de Poesche, una ocupación permanente del mismo territorio desde el Paleolitico. Ambas cosas creía encontrarlas en Escandinavia, donde la Arqueología indicaba una ocupación antigua y sin discontinuidad desde el Paleolitico. Pero Penka, a pesar de su profesión de arqueólogo, también utilizó un par de argumentos lingüísticos: la existencia de la palabra "mar" en el vocabulario común de los indoeuropeos ("mori) demostraría que conocían el mar y por lo tanto había que buscarles un emplazamiento ribereño, como es el de las Penínsulas Escandinavas; igualmente los indoeuropeos habrian tenido término común para el "haya" ("bhagos), lo que demostraría que en su hábitat existía ese árbol: Escandinavia meridional lo conoce en efecto.

Pero el verdadero estandarte de la teoría europea, convertida luego en "tradicional", fue G. Kossinna3, arqueólogo, alemán,

1. Th. Poesche 1878.

2. K. Penka 1883, 1886

3. G. Kossinna 1902. 
interesado en los origenes del pueblo germano, que creyó firmemente haber encontrado la patria originaria de ese pueblo en el norte de Alemania y sur de Escandinavia. Y poco después amplió su horizonte concluyendo que esa sería también la patria originaria de todos los indoeuropeos. De alli habrian partido en sucesivas oleadas hasta los diferentes emplazamientos históricos, pero no todos. Los que nunca se movieron de alli emergerian históricamente como germanos. De manera que los germanos son los únicos indoeuropeos étnica y lingüisticamente puros: al no haberse movido de la patria originaria, no se habrían mezclado con "otras razas" y sus lenguas no habrian sufrido la influencia de otras lenguas.

Con Kossinna se consagra una determinada manera de entender la Arqueología: cada cambio de cultura acaecido en un territorio determinado se explica invariablemente como el resultado de la oleada inmigratoria de un nuevo pueblo.

Otra variante de la teoría europea sitúa la patria originaria mâs hacia la cuenca del Danubio. Uno de sus principales promotores fue el arqueólogo P. Bosch-Gimpera*. Su doctrina puede resumirse así: el núcleo embrionario de los indoeuropeos hay que buscarlo en la Europa mesolitica. Las lenguas de las gentes mesoliticas habrian constituido el fondo ancestral a partir del cual habrian surgido diferentes familias lingũísticas, como las indoeuropeas, las fino-ugrias, el rético y el vasco. Ya en el Neolítico antiguo (hacia el iv milenio a.C.) se habrían comenzado a gestar los diferentes grupos indoeuropeos, que se manifestarian en dos culturas neolíticas: la danubiana y la póntica, surgida como extensión de los indoeuropeos de la Europa centro-danubiana. En el แu milenio la cultura danubiana adquiriría su punto de madurez y se infiltraria en los Balcanes e ltalia. Con movimientos danubianos o pónticos hay que relacionar la aparición de los griegos en Grecia y de los hetitas y luvitas en Anatolia. De las estepas pónticas (que hoy llamamos cultura de los kurganes) saldrian más tarde los indo-iranios; pero también movimientos hacia Europa central, donde se mezclan con poblaciones que ya eran indoeuropeas,

+. P. Bosch-Gimpera 1960 
dando lugar a nuevas culturas (cerámica de cuerdas y hachas de combate). A lo largo de la Edad del Bronce continuarian los movimientos indoeuropeos hasta configurar el mapa de lenguas histórico. El lingūista G. Devoto militó en una postura similar, haciendo gravitar tambien los origenes indoeuropeos en la Europa danubiana-centro-europea.

La teoría europea no es cosa del pasado. Durante la primera mitad del siglo xx reinó ampliamente, aunque con cierta contestación minoritaria. En los años 60 fue todavía sostenida, como acabo de decir, por lingüistas como G. Devoto y arqueólogos como P. Bosch-Gimpera. En la actualidad no tiene muchos seguidores entre los arqueólogos, pero sigue siendo la posición mayoritaria entre los indoeuropeistas alemanes y, en general, todos aquellos de posiciones también conservadoras en otras facetas de la indoeuropeística. De hecho ha sido defendida de nuevo en años más recientes por B. Schlerath', S. Zimmer. Como muchas de las enseñanzas contenidas en manuales, y también gran parte de las ideas divulgadas entre no especialistas, se basan en la teoria europea, merece la pena que nos detengamos un tanto en el desarrollo de sus consecuencias doctrinales.

La teoría europea en su variante tradicional comporta unos esquemas cronológicos e históricos muy determinados. La lengua común se habría hablado en la región ya indicada hacia el 2500 a.C. A partir de ese lugar se habría producido en la Edad del Bronce la indoeuropeización del resto de Europa y del Asia meridional mediante distintas oleadas invasoras, que utilizaban para sus conquistas la superioridad militar que les otorgaba el uso de ciertas tecnologias y, muy en especial, del caballo como instrumento de guerra.

Es obvio que en las Islas Británicas, Francia, la Península Ibérica, Italia, Grecia, Europa oriental, Asia Menor, Mesopotamia. Irản y la India había existido una población autóctona previa a la

5. G. Devoto 1962.

6. B. Schlerath 1973, 1981

7. S. Zimmer 1990 
llegada de los indoeuropeos en la Edad del Bronce que, por hipótesis, no podia ser indoeuropea: la población neolítica que habria conservado su lengua, costumbres y religion hasta las invasiones indoeuropeas.

Sobre ese substrato neolitico se habrian establecido los conquistadores indoeuropeos. Su aportación a esos paises habria sido de diferente cuantia en los planos étnicos, culturales y lingüisticos. En terreno de la población (hoy diriamos de la genética), se habria producido una mezcla de las poblaciones antiguas (pre-indoeuropeas) con las nuevas (indoeuropeas), cuya cuantia no se consideraba pequeña, puesto que se hablaba de verdaderas oleadas invasoras. En el terreno cultural, se habria impuesto en general la cultura de los invasores indoeuropeos (familia patriarcal, dioses celestes, etc.) aunque no habrían faltado pervivencias de lo anterior incorporadas al marco general de la nueva cultura. resultando en ocasiones sincretismos fecundos, como el que se generó en Grecia. En el plano lingüístico, las lenguas indoeuropeas habrian substituido de una manera casi general a las previamente existentes. De hecho, desde que tenemos testimonios escritos, hay en Europa muy pocas lenguas que no sean indoeuropeas: en Italia, principalmente el etrusco; en las Islas Británicas, el picto; en Grecia está la lengua que se escribe con el sistema que llamamos lineal A; y en la Península lbérica tenemos dos lenguas no indoeuropeas: 1) El ibérico, bien documentado en la antigüedad, pero desaparecido con la romanización; 2) El vasco, del que no hay textos escritos de época romana ni prerromana, pero que continúa siendo una lengua viva en nuestros días.

Continuando hacia oriente, Asia Menor se consideró durante más de un siglo el reducto no indoeuropeo por excelencia, en el que las lenguas no indoeuropeas se habrian mantenido vivas al menos hasta el s. v a.C. Tales se consideraban entonces las lenguas de los lidios, los licios y los carios, entre otras.

Aún más hacia oriente, se suponía que los indoeuropeos (iranios e indios principalmente) habrían penetrado tan tarde como el final del II milenio a.C. Las lenguas que habrian parcial- 
mente reemplazado son en parte conocidas para la India porque alli no se produjo, ni se ha producido aun hoy, la completa indoeuropeización, sino que sobreviven, tanto más cuanto más al sur y al este, otros grupos lingūisticos como el drávida y el munda.

En resumen, las lenguas pre-indoeuropeas habrian sido radicalmente eliminadas en Europa por las invasiones indoeuropeas en fecha anterior a la documentación escrita. Sería precisamente en la Península lbérica donde la substitución habria estado menos avanzada en los últimos siglos de nuestra era porque, se decía, los Pirineos constituyen una barrera que debió frenar la penetración de las oleadas invasoras. La indoeuropeización habría sido aquí más tardía y más lenta, con lo que la época de las primeras documentaciones escritas encuentra todavia lenguas pre-indoeuropeas no extintas. El vasco, por supuesto, se consideraba (y se sigue considerando en amplia medida todavia) como un superviviente hispano del conjunto de lenguas pre-indoeuropeas que habria logrado subsistir gracias a su aislamiento en inaccesibles montañas y valles pirenaicos.

Ese estrato pre-indoeuropeo fue bautizado con el nombre de "substrato mediterráneo"; "substrato" porque asi llamamos en Lingüistica a todo estrato sobre el que se asienta uno nuevo recién llegado, y "mediterráneo" porque inicialmente el concepto se acunó para designar las lenguas, culturas y poblaciones que ocupaban la cuenca mediterránea, digamos allá por el ı milenio a.C., cuando, en cambio, Europa central y nórdica (y/o danubiana) sería la patria común y sede ancestral de los indoeuropeos. Cuando las oleadas indoeuropeas alcanzaran el Mediterráneo habrían encontrado alli ese estrato étnico y lingüístico, al que los estudiosos de principios del s. $\mathrm{xx}$ dieron ese nombre genérico y geográfico a falta de uno especifico, étnico o lingưístico.

El substrato mediterráneo, su identidad misma, asi como su contenido concreto han estado siempre llenos de paradojas, vaguedades e incógnitas; y su utilización ha corrido siempre un cierto riesgo de arbitrariedad ya que cualquier atribución léxica o toponímica a su acervo queda siempre fuera del alcance de cual- 
quier posibilidad de comprobación porque, por definición, las lenguas mediterraneas, a las que en hipótesis pertenecería, habrian desaparecido y en consecuencia nos serian radicalmente desconocidas.

Aparte de las lenguas supuestamente supervivientes del estado de cosas pre-indoeuropeo (ibérico, vasco, picto, etc.), se atribuian a dicho substrato principalmente dos cosas:

Una cierta cantidad de léxico real o supuestamente no indoeuropeo, presente en lenguas indoeuropeas del mediterráneo (vino, asno, rosa, liebre, cadàver, mundo, tesoro, caliz, cabello, signo, cuerno, elefante, timpano, copa, cubo, nardo, rosa, pino, ciprés, araña, dragón, lagarto, cocodrilo, toro, etc.).

Una abundante toponimia supuestamente no indoeuropea (nombres derivados de *kar-, * mal-, *lap-, *pal-, etc.). En rigor, a ese estrato habría que atribuir la mayor parte de la toponimia de las Peninsulas Mediterráneas que no se explicara etimológicamente a partir de las lenguas indoeuropeas históricamente presentes en ellas: todo lo no griego en Grecia; lo no latino, osco o umbro en Italia; lo no celta o latino en la Península Ibérica. (Para la Península lbérica se habló de otro componente pre-indoeuropeo adicional que procedería de África, y que se dio en llamar "substrato líbico"). En ocasiones el componente ibérico y el vasco se han asociado a penetraciones de gentes procedentes de África.

Nótese que, dentro de la lógica de la doctrina tradicional sobre la patria originaria de los indoeuropeos, substratos pre-indoeuropeos podrían encontrarse en cualquier lugar de Eurasia menos en dicha patria, donde los indoeuropeos habrian estado asentados "desde siempre". Digamos que en ella el único "substrato" existente era precisamente el indoeuropeo.

2 LAS ESTEPAS DEL SUR DE RUSIA: LA TEORIAA DE LOS KURGANES

El precursor de la línea de pensamiento que ubica la "patria originaria" en las estepas del sur de Rusia es el indoeuropeista $\mathrm{O}$. 
Schrader ${ }^{4}$, quien, como es natural, apoyó sus tesis con argumentos meramente lingūisticos. Habrian de pasar más de treinta años antes de que V. G. Childe aportara algunos argumentos arqueológicos en pro de esa misma ubicación, aunque en realidad una gran parte de su argumentación siguió recayendo en consideraciones de indole lingüistica.

La verdadera argumentación arqueológica tardó en llegar otros treinta años largos y fue obra de M. Gimbutas ${ }^{i 0}$, que identificó la cultura indoeuropea originaria con la de los kurganes, antes llamada de los túmulos, que se desarrolló en las estepas del sur de Rusia durante un dilatado periodo de tiempo, a partir del $v$ milenio a.C.

La teoría de M. Gimbutas no se limita a establecer ese emplazamiento y cultura como la Urheimat de los indoeuropeos, sino que traza todo un cuadro cronológico del proceso de indoeuropeización de Europa y Asia meridional, que puede resumirse como sigue:

Según M. Gimbutas, la cultura de los kurganes manifestaría durante varios milenios una acusada tendencia expansionista. Probablemente de forma ininterrumpida habrian estado produciéndose movimientos migratorios de mayor o menor cuantia, aunque el aliento expansivo habría sido particularmente intenso en tres momentos sucesivos que dieron lugar a las tres grandes migraciones postuladas por la autora. La primera de ellas se habría producido ya en el v milenio a.C. en dirección a Europa, que se vio afectada especialmente en las zonas danubiana y balcánica. El segundo momento de intensa expansión tuvo lugar en la segunda mitad del IV milenio a.C. Durante esos quinientos años los elementos kurgánicos alcanzaron por una parte la vertiente meridional del Cáucaso, Irán y Anatolia; y, por otra, se produjo una nueva penetración en Europa centro-oriental. Finalmente, a principios del il milenio a.C. se produce una penetración hacia Egipto y Palestina.

8. O. Schrader 1890 ,

9. V. G. Childe 1926.

10. M. Gimbutas 1970, 1973a, 1973b, 1977, 1979, 1980, 1982, 1989, 1990a, 1990b. 
La teoría kurgảnica tuvo una amplia aceptación por parte de los indoeuropeistas menos conservadores. La cultura de los kurganes, excavada y sacada a la luz ampliamente por $\mathrm{M}$. Gimbutas, resultó contener casi todos los elementos que la Lingüistica Indoeuropea (en la parcela de su actividad que llamamos "Arqueología Lingưística") demanda para la patria originaria: economia fundamentalmente ganadera basada en caballos, cerdos, vacas y ovejas; existencia de abedules, abetos, álamos, hayas, sauces, robles, etc.; y de animales salvajes como oso, castor, lobo, zorro, etc. Y, por añadidura, alargaba la cronología de la lengua común al menos en un milenio al situar el momento de mayor intensidad expansiva en el rv milenio, cuando se produce la penetración kurgánica en Anatolia por una parte y en Europa por otra.

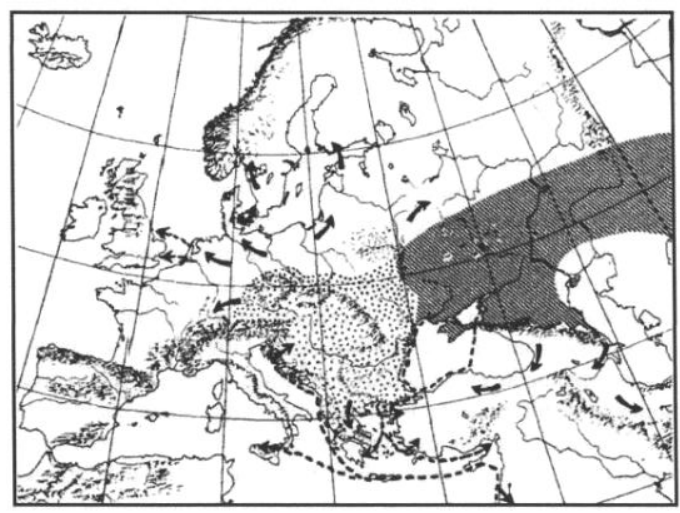

La Urheimat segun M. Gimbulas

En efecto, independientemente del curso que seguía la investigación arqueológica, muchos indoeuropeístas comenzábamos a considerar demasiado corta la cronología del 2500 a.C. para 
la lengua común, sobre todo para hacer encajar en ella la situación de las lenguas anatolias en general y el hetita en particular. Muchos textos hetitas en arcilla datan de los primeros siglos del ॥ milenio a.C. y a veces son copia literal de otros más antiguos inscritos originariamente en madera. Pues bien, ya desde los textos más antiguos se observa una fuerte diferenciación dialectal no sólo entre el anatolio y el resto de las lenguas indoeuropeas, sino de las lenguas anatolias (hetita, luvita, palaita) entre sí, que dificilmente podemos imaginar que se hubiera producido en tan escaso margen de tiempo.

Ambas razones (cuadro cronológico más verosimil y coincidencia de los hallazgos arqueológicos con la Arqueología Lingüistica) hicieron que desde pronto los indoeuropeistas de línea de pensamiento menos condicionada por la tradición adoptáramos la teoría kurgánica como la mảs verosimil de entre las que se nos ofrecian allá por los años 70 y 80 . Y la mayoría de ellos continúan en esa posición, más bien escépticos ante las nuevas corrientes surgidas entre finales de los años 80 y los años 90 .

Obsérvese que las tesis kurgánicas no suponen una verdadera revolución para las ideas recibidas sobre el proceso de indoeuropeización de la mayor parte de Europa y Asia meridional. En efecto, tres de los puntales de la misma quedan más o menos intactos: existencia de densos substratos pre-indoeuropeos de ascendencia neolitica, indoeuropeización por medio de oleadas invasoras que se imponen por el uso del caballo, y época de los metales como contexto cronológico de la indoeuropeización de la mayor parte de Europa y Asia meridional. Efectivamente, cuando, según la versión de M. Gimbutas, los indoeuropeos comenzaron a llegar a Europa y Asia meridional la habrian encontrado ocupada por poblaciones pre-indoeuropeas que les habrian servido de substrato. Naturalmente, al no ser ahora Alemania y el sur de Escandinavia la Urheimat, se entiende que alli habrian tenido que encontrar también substratos pre-indoeuropeos. 


\section{LA INDOEUROPEIZACIÓN NEOLITICA}

También han sido indoeuropeistas quienes han postulado primero una ubicación próximo-oriental de la patria originaria. $Y$ lo han hecho obviamente con argumentos lingüisticos que, sin embargo, no convencieron a los lingüistas, aunque si a diversos arqueólogos. Th. Gamkrelidze y V. V. Ivanov creyeron encontrar argumentos en el léxico común indoeuropeo para suponer que la Urheimat habría estado situada en una región más meridional de lo que previamente habian creído tanto los partidarios del emplazamiento europeo como los kurganistas y propusieron en concreto la zona formada por el sureste de Turquia y el norte de Siria.

Es probable que esta teoría próximo-oriental basada en argumentos lingūisticos no hubiera tenido demasiado eco a no ser por el hecho de que unos años más tarde $C$. Renfrew ${ }^{12}$ expuso su conocida teoría de Asia Menor como la patria originaria, basada en argumentos arqueológicos. Su argumentación lingūistica es poco fundada y está llena de errores e imprecisiones propias de alguien que no es un profesional en la materia; de hecho, ha sido rechazada por la generalidad de los indoeuropeístas. Han sido sus razonamientos arqueológicos los que han logrado una amplia aceptación entre los arqueólogos.

Conviene recordar que C. Renfrew había militado en la corriente de pensamiento procesualista y continuista que se había ido abriendo camino entre los arqueólogos a partir de los años 50 (aunque con precedentes anteriores). Surgida como reacción al invasionismo de Kossinna, esa "Nueva Arqueologia" tendió a atribuir los cambios culturales acaecidos en la prehistoria a procesos internos (procesualismo) y a la difusión de las ideas sin necesidad de desplazamiento de contingentes humanos significativos (difusionismo). Esa postura se habia ido radicalizando hasta alcanzar, como ha hecho también en lo que se refiere al problema indoeuropeo, su formulación maximalista, en la que se niega cualquier

11. Th. Gamkrelidze and V. V Ivanov 1995 (traduccion de un original ruso de 1984).

12. C. Renfrew 1987, 1992, 1997, 1998, 2001 
movimiento de poblaciones después de la primera ocupación de las distintas regiones por el homo sapiens sapiens.

C. Renfrew habia sido un exponente señero de esa tendencia. En su tesis sobre el origen de los indoeuropeos niega los movimientos de pueblos en la Edad del Bronce, de manera que los indoeuropeos no han podido expandirse en esas fechas tan tardias, y eleva a la época neolitica la patria originaria y la expansión de los indoeuropeos; pero adoptó de L. L. Cavalli-Sforza y M. W. Feldman (1981) el concepto de "difusión démica" y lo aplicó al problema indoeuropeo.

Como es sabido, C. Renfrew (1987) ubica la patria originaria en lo que actualmente es la Turquía central, justo donde supone que apareció por vez primera la agricultura y se produjo la transición neolítica hacia el 7000 a.C. Esos "inventores" de la agricultura serían precisamente los indoeuropeos. La indoeuropeización no se habría producido mediante oleadas invasoras como pretendían la doctrina tradicional y kurgánica, sino con arreglo a un nuevo modelo de la difusión démica.

Por difusión démica explicaba Renfrew en 1987 la indoeuropeización de casi toda Europa y de Asia meridional. Desde los primeros momentos de la agricultura la población habría comenzado a crecer y a expandirse hacia los terrenos adyacentes a un ritmo calculado por L. L. Cavalli-Sforza y M. W. Feldman de un

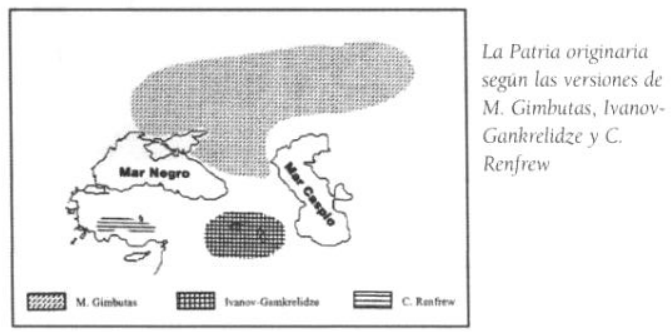


kilómetro de media por año. Mediante ese crecimiento natural de la población en pocos milenios los indoeuropeos se habrian visto asentados en todos los emplazamientos históricos, desde Gran Bretaña hasta la India, y desde los Paises Nórdicos o Băticos hasta la Penínsulas Mediterráneas.

L. L. Cavalli-Sforza y sus colaboradores han defendido durante años que en el Neolítico se produjo una difusión démica desde el Oriente Próximo hacia Europa que habria supuesto un verdadero vuelco en la composición étnica y genética de nuestro continente. En el plano genético tendria su reflejo en el gradiente del componente principal 1, cuya zona de mayor densidad está precisamente en el Próximo Oriente y va descendiendo a medida que aumenta la distancia.

Los cazadores-recolectores mesolíticos, escasos en número y con inferior tecnologia, habrian sido sumergidos por la población neolitica. Según Renfrew ${ }^{17}$, la densidad de su población habria sido

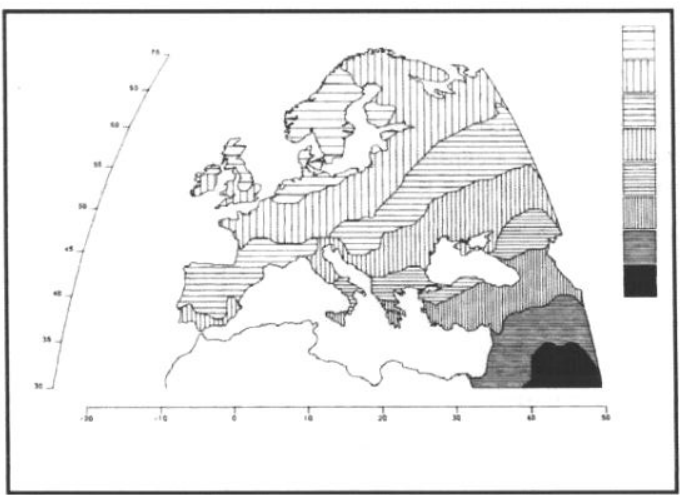

Mapa sintético de CP 1

(Cavalli-Sforza, Menozzi and Piazza 1994, p. 292)

13. C. Renfrew 1987, p. 150 
tan escasa que apenas habria llegado a constituir un $1 \%$ del conjunto de la población de la mayoría de las áreas neolitizadas. En tales circunstancias habrian sido absorbidos por los agricultores y asimilados lingūísticamente, de manera que de sus lenguas sólo habría quedado algún léxico de substrato. Solamente en algunos lugares en que la población mesolítica fuera más densa, cosa que ocurriria, según Renfrew, por ejemplo en las costas de Portugal, su contribución pudo llegar a ser localmente mayor: la propia población mesolítica pudo allí adoptar la agricultura, crecer rápidamente en número y mantener asi ocasionalmente su lengua. Probablemente esa seria la explicación de la supervivencia del vasco y del etrusco, y quizá de muchas otras que luego pudieron irse perdiendo paulatinamente.

La tesis de Renfrew, asociada a la genética de poblaciones de la escuela de Cavalli-Sforza, haría predecir que, salvo en lugares concretos donde hubiera habido una densidad excepcional de población mesolitica, el pool genético de Europa seria masivamente neolítico puesto que procede de una población compuesta de $99 \%$ de gentes neolíticas y un $1 \%$ paleolítica o mesolítica. Esa idea reinó durante un tiempo también en el campo de la genética de poblaciones. Pero en los últimos años las cosas han dado un vuelco espectacular, de manera que las ideas ahora vigentes, basadas en el estudio del ADN mitocondrial y del cromosoma $\mathrm{Y}$, establecen que el pool genético de Europa es bastante uniforme y se compone en un $80 \%$ de estirpes genéticas que datan del Paleolítico y tan sólo un $20 \%$ del Neolítico.

Para los indoeuropeístas las tesis de Renfrew tienen graves dificultades por su incompatibilidad con muchas de las convicciones vigentes entre la inmensa mayoría de nosotros. Si las cronologías de la teoría kurgánica son difíciles de aceptar para los indoeuropeístas conservadores, las de Renfrew y su indoeuropeización neolítica nos ponen en dificultades a todos en general $^{1+}$.

14. Unos pocos linguistas, como M. Alinei (1997-2000) y X. Ballester (2002), aceptan esas cronologias e incluso otras mas elevadas, como veremos mas abajo. Sin embargo. eso no invalida mi afirmacion ni el uno ni el otro son indoeuropeistas Por otra parte, W. P. Lehmann (2002) eleva la perspectiva de su reconstruccion hasta el 8000 a.C. pero siendo consciente de que lo que reconstruye para esa fecha no es ya indoeuropeo. sino un estado de lengua muy anterior que llama "pre-proto-indoeuropeo". 
Y el problema no es sólo de cronologia, sino también de diversos otros aspectos, que van desde la dialectología indoeuropea hasta el léxico común como indicio de la patria originaria y la cultura originaria. Pero sobre los argumentos lingüisticos a favor o en contra de cada una de las tesis sobre la patria originaria volveré más abajo.

De todas formas las posiciones del propio C. Renfrew se han ido modificando paulatinamente en respuestas a las criticas que ha ido recibiendo desde que fueron sostenidas por vez primera. A partir de 1992 Renfrew $^{15}$ ha ido aplicando sus ideas sobre la expansión de las lenguas indoeuropeas al cuadro general de la difusión de las lenguas en el mundo: todos aquellos grupos lingũisticos que presentan una distribución amplia en el mundo se habrian expandido en el momento de la implantación de la agricultura en sus respectivas áreas, como resultado de los cambios sociales, económicos y demográficos que esta supuso ${ }^{16}$ Las lenguas habladas en las äreas que fueron importantes en la domesticación de plantas y animales quedan asociadas a la difusión de la nueva economía, bien a través de difusión démica, bien a través de un proceso de cambio de lengua debido al contacto. Para Europa ese punto fue obviamente Anatolia, desde donde se habrían difundido conjuntamente la agricultura y las lenguas indoeuropeas.

En la última versión que le conozco ${ }^{17}$, sigue proponiendo que Grecia, Creta, los Balcanes y la región danubiana fueron indoeuropeizadas a la vez que neolitizadas hacia 6.500 a.C. por difusión démica. Pero ahora opina que el resto de Europa lo habría sido por el modelo alternativo del "cambio de lengua por contacto". Por su parte, los indios e iranios, que habrían estado asentados inicialmente en el área septentrional del Mar Negro, incluida Ucrania, habrían penetrado en el altiplano iránico y luego en la India gracias al "impiego del cavallo per tirare il carro con ruote e

15. C. Renfrew 1992, 1996, 1998

16. J. Diamond and P. Bellwood 2003.

17. C. Renfrew 2001 
raggi, e sucesivamente dallo sviluppo della caballería e dell'equitazione per scopi militari"is.

La primera posición de Renfrew suponia una ruptura del marco general de la indoeuropeización de Europa sostenido hasta entonces. Me refiero principalmente a la idea de que los indoeuropeos, llegados en la edad de los metales, se habrian asentado en todas partes (menos, claro está, en la patria originaria) sobre un estrato de población neolítica, a la que no habrian exterminado sino que se habrian mezclado con ella. Dentro de las coordenadas de la teoría de los kurganes, debería encontrarse ese tipo de substrato neolítico en toda Europa (incluida la central y la nórdica) y en Asia meridional, pero no en las estepas del sur de Rusia. En la versión originaria de Renfrew ${ }^{15}$ no habría ningún substrato neolítico de carácter pre-indoeuropeo en ningún punto de Europa, porque lo neolitico era precisamente lo indoeuropeo.

Como decia, la verdadera ruptura con la concepción sobre la indoeuropeización de Europa, vigente entre los lingüistas, se produce con C. Renfrew, no con M. Gimbutas. Y probablemente esté ahí la clave de por qué la una tuvo tanto éxito entre ellos y el otro tan poco.

Las implicaciones de la nueva versión de Renfrew respecto al substrato mediterráneo en general $y$ a la toponimia en particular son menos claras. En realidad, como ya he dicho, en su primera versión ${ }^{20}$ había admitido que en la Península lbérica y en Italia se hubiera producido una neolitización de las poblaciones mesoliticas bien por procesos internos, bien por aculturación, sin que hubieran perdido sus lenguas autóctonas, que serian no indoeuropeas (pre-indoeuropeas). Por ese camino explicaba el ibérico, el vasco y el etrusco. La neolitización habría permitido a esas gentes pre-indoeuropeas un incremento de población que a su vez habria posibilitado el establecimiento de una hidro-toponimia densa no-indoeuropea, diferenciándose así esos territorios de los de Europa

\footnotetext{
18. C. Renfrew 2001, p. 123

19. C. Renfrew 1987

20. C. Renfrew 1987, p. 268
} 
central y centro-oriental, donde su equivalente habria de ser indoeuropeo.

En su nueva posición extiende la neolitización por aculturación de las poblaciones mesoliticas a toda la Europa que no lo había sido previamente por difusión démica. Y esa aculturación hubo de ser completa, incluyendo la lengua en la mayor parte del territorio implicado. Sin embargo, un "cambio de lengua" por contacto, y más aún en tan gran escala como esa posición exige, es aún más inverosímil que la substitución masiva de lenguas pre-indoeuropeas por obra de elites dominantes, como postulaba M. Gimbutas.

\section{LA INDOEUROPEIDAD PALEOLITICA}

La última teoría sobre el origen de los indoeuropeos y la indoeuropeización de Europa y Asia meridional eleva la cronologia del proceso hasta el Paleolitico. Primero fue en el ámbito de la Arqueologia ${ }^{21}$ donde se postuló que los indoeuropeos se extendieron por sus sedes históricas ya durante el Paleolítico.

M. Otte hace de los cambios climáticos la causa del proceso de indoeuropeización de Europa. Los últimos 100.000 años han estado marcados por una larga serie de oscilaciones climáticas drásticas ${ }^{12}$, cada una de las cuales fue capaz de producir cambios igualmente drásticos en la densidad de la población al alterarse la base de sus recursos para la subsistencia. Durante los períodos de frío intenso y sequedad la población decrecería, e incluso se extinguiría en las zonas menos favorecidas, para verse a continuación rápidamente incrementada en periodos de bonanza.

En estos últimos, las poblaciones que hubieran sobrevivido en lugares templados habrían podido expandirse a las zonas adyacentes, que habrian quedado deshabitadas. Ese proceso debió suponer la desaparición de numerosos grupos étnicos y la extinción de numerosas lenguas, propiciando en cambio la rápida expansión de otros y otras. Uno de los grupos de lenguas que 
experimentó una expansión de esas características habria sido el grupo indoeuropeo.

La posición de Otte es muy poco dogmática. En primer lugar, él reconoce simplemente que su tesis es una mera especulación ${ }^{23}$. En segundo lugar, admite toda una serie de posibilidades cronológicas a partir de 12.500 a.C., fecha en que se produce el primer período de calor post glaciar. Finalmente, aunque cree en la probabilidad de que las lenguas indoeuropeas se expandieran efectivamente en esas fechas paleolíticas, considera que las otras dos teorías alternativas no tienen por qué ser falsas: las tres, que él llama respectivamente "battle-ax", "farming wave" y "sparse wave", pueden representar otros tantos episodios del complejo proceso de expansión de las lenguas indoeuropeas.

En realidad, bajo ciertos supuestos, los indoeuropeístas no encontrarian inconvenientes decisivos para admitir la posición de Otte. Que hacia el 10.000 o el 12.000 a.C. la indoeuropea fuera ya una familia separada de los demás grupos lingüisticos y se hubiera extendido por ciertas zonas de Eurasia no podria ser objeto por parte de la Lingüistica Indoeuropea de ninguna objeción razonable, excepto la que el propio Otte se hace asi mismo: es una tesis meramente especulativa, tan verosímil como dificil de corroborar ni siquiera de forma indiciaria. Los indoeuropeístas se limitarían a precisar que en todo caso el estado de lengua hablado por esos antepasados indoeuropeos no sería el recuperable por reconstrucción comparativa a partir de las lenguas históricas; e, igualmente, que los dialectos indoeuropeos históricamente conocidos no se habrian separado a partir de ese estado de lengua, sino de otro más moderno.

Tampoco sería contrario a la tesis de Otte el vocabulario común de la fauna y de la flora de clima frío, porque por hipótesis el Levante durante los períodos fríos, aunque con un clima más favorable que otros puntos de Europa, de Asia Menor o de los Balcanes, habria respondido bien a las características exigidas por ese vocabulario.

23. J. Adams and M. Otte 1997 
La posición de los pocos lingūistas que por ahora han defendido la indoeuropeización paleolítica es mucho más drástica y revolucionaria que la de Otte, y sus implicaciones son mucho más claras y de largo alcance para los substratos prehistóricos y la toponimia antigua. El principal defensor de la "teoría de la continuidad" con argumentación lingūistica ha sido $\mathrm{M}$. Alinei ${ }^{2+}$.

La propuesta de Alinei es que las lenguas indoeuropeas se extendieron por todas sus sedes históricas, tanto europeas como sud-asiáticas, como resultado de la expansión del homo sapiens desde África, individuadas ya como lenguas indoeuropeas y separadas por lo tanto de todas las demás familias (semítica, camítica, uránica, etc.), con las que en realidad nunca habrian formado una unidad intermedia. Las lenguas indoeuropeas, como todas las demás familias, se habrian asentado desde el primer poblamiento en los territorios en que luego aparecen históricamente. Después de ese primer asentamiento sólo habria habido pequeños reajustes meramente regionales.

En realidad, la Genética de poblaciones nos habla en la actualidad de dos momentos diferentes en que la humanidad se ha esparcido desde África hasta los demás continentes: 1) La diáspora más antigua tuvo lugar hace entre 1,5 y 1 millón de años; con ella se esparciría por el viejo mundo el homo sapiens arcaico; 2) La diáspora reciente, la del homo sapiens sapiens, que se habría producido en torno al 100.000 a.C.

$\mathrm{El}$ asentamiento en Europa de los sapientes arcaicos de la primera diäspora debe cifrarse para M. Alieni hacia el 500.000 a.C. ${ }^{25}$, el de los sapientes sapientes de la segunda habría tenido lugar hacia el 60.000-50.000. ¿Cuál de los dos poblamientos supuso la implantación en Europa de las lenguas indoeuropeas? Alinei no quiere pronunciarse definitivamente al respecto y prefiere dejar la elección a paleoantropólogos y genetistas. No obstante, en atención a diferentes consideraciones que no puedo aquí reproducir, considera preferible la teoria de la continuidad "larga", es decir: que el asentamiento de las lenguas indoeuropeas en Europa seria

24. M. Alinei 1996-2000, 2001

25. M. Alinei 1996-2000, v. I. p. 494 
el resultado de la primera diáspora. Bajo esa hipótesis, el autor quedaria adscrito a la teoria multirregional del homo sapiens sapiens, porque en la primera diáspora de África salió el homo sapiens arcaico, que se habria trasformado en sapiens sapiens independientemente en varias regiones. Concretamente en Europa el hombre de Neandertal sería no sólo homo loquens, sino homo loquens indogermanicus, que habria evolucionado sur place hasta el sapiens sapiens. Naturalmente Alinei sabe que esa tesis, aunque aún tiene adeptos, pierde terreno día a día ante el avance de los argumentos de la Genética de poblaciones. Por ello deja el tema abierto y en manos de genetistas y antropólogos. Obviamente si resulta cierta la tesis del out of Africa del hombre moderno hace unos 100.000 años y del consiguiente reemplazamiento universal del homo sapiens arcaico por el sapiens sapiens, Alinei se verá llevado a aceptar la versión corta de su teoria de la continuidad.

Debe entenderse que los cambios culturales posteriores (agricultura, metalurgia, etc.) se han producido por evolución interna y aculturación de las distintas poblaciones, sin que esos procesos hayan comportado cambios importantes en la distribución ni de los genes ni de las lenguas.

Naturalmente, se aprecia a simple vista que la dificultad para Alinei es explicar la presencia en Europa del etrusco, el vasco y el ibérico. En general, para las lenguas hasta ahora tenidas por "pre-indoeuropeas" hace una afirmación genérica que merece la pena transcribir: "LEuropa sarebbe stata occupata da popolazioni indoeuropee tanto presto quanto la paleontología e le scienze affini ci permettono di assumere, assieme a popolazioni uraliche e ad altre popolazioni non indoeuropee. Queste popolazioni non indoeuropee, tuttavia, non sarebbero più pre-indoeuropee, come nella teoria tradizionale, ma diventerebbero peri-indoeuropee"20. En su concepción de las cosas, las lenguas no indoeuropeas presentes en Europa, ayer $\mathrm{u}$ hoy, o bien penetraron yuxtapuestas a las indoeuropeas en el primer poblamiento (urálicas), o bien son el resultado de movimientos locales de cuantia menor en el Neolítico 
(vasco, ibérico, etrusco) o de penetraciones aún más tardias e igualmente locales (húngaro)

\section{LINGUUISTICA COMPARATIVA Y PROBLEMA} INDOEUROPEO

Debo recordar, para comenzar el discurso, que el concepto de "indoeuropeo" es meramente lingüistico: son pueblos indoeuropeos aquellos que hablan una lengua indoeuropea, independientemente de sus medidas cefálicas, su cultura material, sus creencias religiosas o su ubicación geográfica. Sólo los indoeuropeistas están capacitados para establecer qué lenguas son o no son indoeuropeas. mediante la utilización de un método exclusivamente lingūistico. que llamamos Método Comparativo.

La primera consecuencia, todavía estrictamente lingùisti$\mathrm{ca}$, del parentesco entre las lenguas indoeuropeas consiste en que todas ellas son transformaciones en el tiempo de una lengua más antigua que está respecto a ellas en la misma o parecida relación que el latín lo está respecto a las lenguas romances. En este punto la generalidad de los indoeuropeístas está de acuerdo. Ya hemos visto más arriba que $\mathrm{M}$. Alinei, lingúista no indoeuropeísta, se aparta de nosotros en ese punto capital, lo que tiene una catarata de consecuencias de hondisimo calado. Los indoeuropeistas podemos discrepar, y de hecho lo hacemos, sobre la forma precisa en que se concibe la lengua común ancestral (más o menos unitaria, más o menos reconstruible, más o menos dialectalizada desde el principio, conglomerado de dialectos contiguos, etc.). Pero es necesario partir de un estado de lengua más homogéneo que el histórico. Y esa mayor homogeneidad prehistórica implica un espacio geográfico originario más limitado que el históricamente ocupado por las lenguas de la familia. No hay ningún indoeuropeista que no lo acepte asi: es la base misma de la Linguística Histórico-Comparativa.

Pero, obviamente, esa primera consecuencia lingüistica tiene una importante implicación histórica, que podria formular- 
se asi: los pueblos indoeuropeos se encuentran desde los albores de la historia ocupando casi toda Europa, Asia menor, Oriente Medio, buena parte de la India, más algún otro enclave asiático. Como no es posible imaginar que han estado en todos esas regiones desde siempre, porque la propia presencia de la especie humana en ellas tiene un límite, resulta obligado pensar que han llegado hasta alli desde algún lugar y en algún momento. El encontrar el lugar de origen de los indoeuropeos (donde), fijar el momento (o los momentos) en que se produjo su expansión (cuándo) y establecer la forma en que esta se produjo (cómo) constituyen la vertiente histórica del problema indoeuropeo.

Lo que inicialmente era una cuestión de lingūistas transciende así ese ámbito ya que la respuesta a esas tres preguntas necesitará poner a contribución métodos, técnicas y conocimientos de otras disciplinas, concretamente la Historia y la Arqueología, a las que ahora se incorpora esperanzadoramente la Genética de poblaciones. Se convierte asi el problema en interdisciplinar: arqueólogos y lingüistas y genetistas, andando por caminos diferentes y empleando métodos heterogéneos, necesitan llegar a soluciones aceptables para unos y otros. Pero como cada uno de esos grupos suele trabajar con las perspectivas y los métodos de su sola disciplina, los tratamientos del problema resultan de ordinario parciales.

Los aspectos históricos y arqueológicos del problema indoeuropeo son competencia exclusiva de historiadores y arqueólogos; pero con la condición de que satisfagan un inventario minimo de requisitos que la Lingūistica Histórico-Comparativa impone. Esa condición es difícil incluso de formular en términos precisos, porque la Lingüistica Histórica no es una ciencia exacta. y ello tiene como resultado el que no todos los indoeuropeístas estén de acuerdo en el inventario de esas exigencias. Por ello no es posible ofrecer para uso de arqueólogos, historiadores y genetistas una lista completa de las exigencias mínimas que debe cumplir cualquier teoría sobre la difusión de las lenguas indoeuropeas. Pero sí daré algunas de ellas. 
Cualquier teoría que pretenda explicar la extensión de las lenguas indoeuropeas en Eurasia ha de dar respuesta a las tres cuestiones capitales: cuándo, dónde y cómo. Y la Lingüistica HistóricoComparativa tiene ciertas exigencias sobre cada una de ellas.

1.- Cuändo. La fecha en que se situe el inicio del proceso deberá encontrarse dentro de unos límites que resulten congruentes con los fenómenos lingüisticos implicados. En concreto, es imprescindible un marco cronológico dentro del que sea posible la transformación de una lengua común indoeuropea (concíbase como se conciba) en la colección de lenguas históricas con un grado muy concreto de alejamiento dialectal. Y ello implica unas limitaciones temporales por arriba y por abajo.

Por abajo hay un limite objetivable en términos de cronología absoluta: la etapa de comunidad tiene que ser necesariamente anterior a la existencia de cualquiera de las lenguas históricas diferenciadas. En el siglo xix y principios del xx ese limite mínimo se ubicaba en el tránsito entre el 11 y el I milenio a.C., con los Vedas y los poemas homéricos como primeras lenguas atestiguadas. En la actualidad ese limite objetivo minimo tiene que situarse mil años más atrás a causa del micénico $y$, sobre todo, de las lenguas anatolias del II milenio a.C.; es decir, en el año 2000 a.C. aproximadamente. Pero, tomando en cuenta los nombres de reyes anatolios contenidos en las tablillas capadocias, la prudencia invita a pensar que hacia 2300-2200 a.C. hay ya al menos una variedad de lengua indoeuropea diferenciada (la variedad anatolia) y, por lo tanto, esa última fecha es el límite minimo objetivo que hoy tenemos que tomar en consideración.

Cuando en el siglo XIX y principios del xx se tenía como límite objetivo mínimo el tránsito entre el 11 y el I milenios a.C., los indoeuropeistas situaban la unidad indoeuropea hacia 2500 a.C. (III milenio), en la idea de que el paso entre la lengua común y las más antiguas formas históricas diferenciadas que entonces se tenian como referencia (griego y sánscrito) exige un considerable lapso de tiempo. El estado de las lenguas anatolias, que hoy nos sirven de referencia para este propósito, exige sin duda también un 
cierto tiempo para su diferenciación. Pero aqui tengo que advertir que existe una disparidad de opinión entre los lingùistas, que se dividen en dos grandes grupos. Unos, los más tradicionales, condicionados acaso por ciertos atavismos de la propia disciplina a los que ya me he referido, siguen ubicando la unidad indoeuropea, a pesar de las lenguas anatolias, en el in milenio a.C., igual que se ha venido haciendo desde el siglo pasado. Otros opinamos que es necesario un mayor espacio de tiempo, de forma que hacemos retroceder la unidad indoeuropea previa a la separación de la rama anatolia a una etapa anterior.

Pero junto al minimo posible hay también un máximo posible, aunque infortunadamente mucho menos objetivable. En efecto, el estado de proximidad dialectal que las lenguas indoeuropeas muestran hacia el principio de la era cristiana no permite un periodo de desarrollo por separado ilimitadamente largo. Las lenguas evolucionan y se transforman de manera ininterrumpida. Y ese cambio, si se produce acompanado de distanciamiento geográfico, se traduce en alejamiento dialectal. Es cierto que, al contrario de lo que sucede con las mutaciones en Genética, no existe una ratio constante en las innovaciones lingüisticas ni, por lo tanto, en el alejamiento entre dialectos emparentados, que es su resultado. Por el contrario, los ritmos pueden ser muy diferentes, y de hecho hay periodos de mayor celeridad que otros. Pero no por ello deja de ser cierto que hay determinados límites en las posibilidades.

2.- Dónde. La Arqueología lingūistica, basada en el estudio del vocabulario común, apoya la ubicación de la patria originaria en una región con fauna y flora de tipo septentrional, lo que sería compatible tanto con las tesis centro-europeas como con las kurgánicas. E incluso lo serían con las de M. Otte, como ya hemos visto. En cambio, lo son difícilmente con la fauna y flora minorasiática, a pesar de los esfuerzos realizados por Th. Gamkrelidze y V. V. Ivanov ${ }^{27}$ para hacerlo verosímil. 
Pero hay otro rasgo del vocabulario común que resulta tan pertinente en este problema como el de la fauna y la flora. Me refiero al hecho de que el léxico común relacionado con la agricultura sea más bien escaso, lo que resulta difícilmente compatible con la tesis neolitica, según la cual los indoeuropeos serían esencialmente los inventores de la agricultura, actividad que habria sido el rasgo más importante y característico de su economia y de su sociedad.

Que el pueblo inventor y difundidor de la agricultura careciera de un vocabulario abundante y especifico para designar los elementos y técnicas de la actividad agraria sería tan impensable como que en inglés, lengua del pais en que se han inventado la mayoria de los deportes modernos, no existieran términos para designar los diferentes deportes, los utensilios y demás elementos de la actividad deportiva. Muy al contrario, si la agricultura hubiera sido inventada y extendida por los indoeuropeos, el vocabulario agrícola no sólo sería indoeuropeo, sino que las lenguas no indoeuropeas de los pueblos que fueron aprendiendo y adoptando la agricultura habrian adoptado ese vocabulario de origen indoeuropeo, de la misma manera que fútbol, paddle, golf, córner o penalty son anglicismos en la mayoría de las lenguas modernas.

Paradójicamente, la escasez de léxico agrícola, que infirma la tesis neolitica, deja indemne la teoria de la continuidad: tanto en el escenario de M. Otte como en el de M. Alinei no podría existir un vocabulario común agrícola porque cuando se instauró la agricultura los grupos indoeuropeos estaban plenamente diferenciados y asentados en sus sedes históricas. Separados unos de otros, crearon de forma independiente dicho vocabulario cuando cada uno de ellos aceptó la agricultura.

3.- Cómo. El cómo se refiere obviamente a la forma en que las lenguas indoeuropeas se han extendido de hecho por toda Eurasia. Inicialmente, en el siglo xIX, se imaginaba invariablemente el proceso como resultado de grandes migraciones. Y, ya en el xx, el arqueólogo alemán G. Kossinna representó la posición extrema, en la que cada cambio cultural habido en un territorio se 
explicaba como resultado de la migración de un nuevo pueblo. Una reacción lógica de arqueólogos posteriores ha llevado a desvincular cambio cultural de migración, de forma que se admite hoy comúnmente que las innovaciones culturales y los progresos técnicos pueden difundirse de un pueblo a otro sin necesidad de que ello implique traslados significativos de población. Esa idea es tan razonable que parece de sentido común. $Y$ uno más bien se pregunta cómo ha podido operar la Arqueología del pasado durante décadas sin tenerla presente. Pero el aceptar como obvio que las innovaciones culturales y los progresos técnicos pueden difundirse sin migración no implica que tales cambios y progresos no se deban nunca a migración. Y, sin embargo, alguien ajeno a la Arqueologia, como yo, tiene la impresión de que en esa ciencia ha operado desde hace tiempo la, al parecer, inevitable ley del péndulo, que la ha llevado desde la vieja posición de Kossinna (todo es migración) hasta la igualmente extrema de no pocos arqueólogos que parecen negar en la práctica toda migración, apoyados en el supuesto de que en las zonas involucradas por la expansión indoeuropea no se han dado desde el Neolítico alteraciones culturales lo suficientemente drásticas y profundas que exijan un cambio de población y de lengua.

Cuando en el ámbito de la Arqueología reinaba en general el modelo de las migraciones, los lingüistas no encontraban graves reparos que hacer en ese punto concreto a las sucesivas propuestas de arqueólogos e historiadores. En cambio, me temo que tenemos dificultades mayores con las hipótesis surgidas en el seno de la corriente arqueológica difusionista. Naturalmente, insisto una vez más, son los arqueólogos los únicos capacitados para explicar el cuadro histórico de la extensión de las lenguas indoeuropeas. Pero, como también he advertido ya, con la condición de que respeten ciertas exigencias que impone la Lingüística Histórico-Comparativa y, a veces, la naturaleza misma del lenguaje humano. Los hechos culturales - pongo por caso una técnica metalúrgicapueden difundirse sin ningún traslado significativo de población. Bastaría con que uno o unos pocos artesanos procedentes de algu- 
na región minorasiática se establecieran en Europa central y ejercieran alli su técnica para que algún tiempo después esa técnica metalúrgica estuviera extendida por Europa sin que se hubiera producido ningún cambio en la composición étnica ni lingũistica. Pero cuando se trata no de una técnica, sino de lenguas o de genes, las cosas son muy diferentes. La lengua materna no se abandona fácilmente, ni por parte de los individuos ni por parte de las poblaciones. El hipotético artesano o pequeño grupo de artesanos hubiera sido capaz de extender su técnica metalúrgica en Europa; pero habria tenido que aprender la lengua de la comunidad en que se hubiera asentado. La comunidad, en cambio, no habria aprendido la de ellos. Todo lo más, habría aceptado en su vocabulario determinadas palabras de la de los artesanos, particularmente las relativas a la nueva técnica. Para que un pueblo abandone su propia lengua y adopte otra hace falta al menos el núcleo de inmigración mínimo para constituir una elite dominante, como sucedió en el caso de los romanos en la Península Ibérica. Y, si se trata de genes, una elite dominante no será capaz tampoco de cambiar el pool genético de un pueblo sino que dejará a lo sumo algunos indicios, porcentualmente menores, de su presencia en el territorio.

Aunque contrarie las tendencias actuales de la Arqueologia, la extensión de lenguas indoeuropeas desde una zona limitada exige, por la naturaleza misma del lenguaje humano y por la forma en que este se aprende o se adopta, movimientos de población significativos. Y cualquier teoria arqueológica que intente obviar esa exigencia contará con la desconfianza o el rechazo de la mayoría de los indoeuropeístas. Me temo que la "aculturación completa", si por ese término se intenta mencionar una que incluya la pérdida de la lengua propia por medio de meros contactos culturales, no resulta una explicación satisfactoria para explicar en gran escala la indoeuropeización de Europa centro-occidental, occidental, nórdica y meridional, como pretende $\mathrm{C}$. Renfrew en la última versión de su doctrina ${ }^{28}$. 
Pues bien, la teoria kurgánica satisface las exigencias de la Lingũistica Histórico-Comparativa también en lo tocante al como. Por su parte, el crecimiento celular del núcleo neolítico originario desde la Península Anatólica hasta indoeuropeizar Eurasia, en la forma en que lo propuso originariamente $\mathrm{C}$. Renfrew, al comportar un avance lento de la propia población, satisface también esa exigencia primaria. Pero, de haber sucedido así las cosas de hecho, ello tendría unas implicaciones lingüisticas de otra indole que, en cambio, no satisface. En efecto, esa especie de avance celular de la indoeuropeidad, como una lenta ola, exigiría una conexión dialectal inmediata, grupo a grupo, de todos los dialectos indoeuropeos, en un gradiente continuo, con zonas de transición entre una y otra lengua, de forma que la mayor proximidad lingúistica se daría entre las lenguas geográficamente más cercanas y el mayor alejamiento dialectal se encontraría entre las lenguas fisicamente más distantes.

El mapa dialectal de las lenguas indoeuropeas dista mucho de ofrecer el citado gradiente. Las lenguas dialectalmente más próximas entre si están en ocasiones muy distanciadas geográficamente. Y, en cambio, a veces hay en vecindad lenguas bien diferentes. Así, por ejemplo, en la teoría de Renfrew, el griego debería ser un dialecto próximo a los de Europa Occidental que, en rigor, de alguna forma habrían salido de él. Sin embargo, el griego se aleja fuertemente desde un punto de vista lingüístico de las lenguas occidentales, para vincularse dialectalmente con el indo-iranio. Otro ejemplo: recientemente el celtista K. H. Schmidt ${ }^{29}$ ha puesto de manifiesto con sólidos argumentos que el celta no tiene vinculaciones dialectales especiales con ninguna de las lenguas de Europa central ni occidental y, en cambio, se conecta lingưisticamente con el griego e indo-iranio.

Lo que acabo de decir no impide que exista una cierta continuidad dialectal que, aunque más bien difusa y con determinados saltos y discontinuidades, ha permitido el florecimiento de toda una línea de la Dialectología indoeuropea basada en las rela-

29. K. H Schmidt 1991 
ciones espaciales. Me refiero a la teoria de las ondas, formulada por vez primera por J. Schmidt ${ }^{0}$ en el s. XIX y continuada luego por A. Meillet "y numerosos indoeuropeistas italianos en el s. XX. La posición de Meillet, que ha gozado de amplia aceptación especialmente dentro de la escuela francesa, puede resumirse en estas palabras suyas:

Les parlers indoeuropeens occupaient une aire où les innovations linguistiques avaient lieu d'une manière indépendante sur des domaines contigus, sans quil y eât nuile part une limite qui séparât entièrement certains groups de certains autres. Et, quand la séparation s'est produite sans doute progressivement, c'est-à-dire quand des colons et des conquérants sont allés occuper des domaines nouveaux auxquels ils ont impose leur langue, il n'y a pas eu de dislocation dans la disposition respective des langues $[\ldots \mid$ rien nindique que les anciens parlers aient $|. .$.$| inverti leur places respectives$

Una visión dialectal como esa, basada sin duda en sólidos argumentos lingüísticos, carece sin embargo de un trasfondo histórico real. Como algún lingüista ironizó al respecto, esa imagen es tan irreal en términos históricos que parece considerar las lenguas como si fueran soldados que se ejercitan en el patio del cuartel y después de largos recorridos terminan cada uno en la vecindad del que tenía antes de comenzar los movimientos.

En realidad, las relaciones dialectales de las lenguas indoeuropeas son enormemente complejas y sugieren un proceso de indoeuropeización igualmente complejo, resultado de múltiples sucesos en etapas cronológicas varias y no de un suceso único como la neolitización.

Comentario aparte merece la teoría de la continuidad. Como ya dije más arriba, sólo puede ser aceptada si media una negación de la validez del Método Comparativo y una ruptura con la concepción de la evolución lingüística en que este se apoya. De hecho no conoz-

30. J. Schmidt 1872

31. A. Meillet 1950, p. 134

32. A. Meillet 1950, p. 134-135. 
co ningún indoeuropeista que haya realizado ya esa ruptura o se sienta tentado a realizarla. Si alguno lo hiciera dejaría eo ipso de ser indoeuropeista en el sentido que hasta ahora viene teniendo esa especialidad cientifica, para convertirse en un lingüista de otra especie que está por advenir. No es por ello casual que quien la ha propuesto no sea, como dije en su momento, un indoeuropeista, a pesar de ser un lingüista cualificado en otras provincias de la disciplina.

La teoria de la continuidad es una manifestación extrema de la tendencia procesualista indigenista, proclive a explicar los cambios culturales como resultado de meros procesos internos, que ha tenido amplia aceptación entre los arqueólogos en las últimas décadas. Como lingûista que soy, tengo poca autoridad en cuestiones arqueológicas, de manera que cederé la palabra a A. J. Ammermann ${ }^{13}$ para formular un juicio valorativo del continuismo:

Nella bibliogralia degli anni ottanta relativa all'archeologia, non e raro trovare ipotesi generali di continuita tra il Mesolitico e il Neolitico in Europa. Poche di queste ipotesi, però, sono ben sostenute [...] e la magior parte puó essere oggi considerata come espressione della moda dell'indigenismo a un dato momento e non come cio che si poteva realmente dedurre dai dati archeologici.

33. A. J. Ammermann 2001, p. 39 
ADAMs, J. and M. OTHE (1997): "Did Indo-European Languages spread before farming?", Current Anthropology (in press: http://www.esd.ornl.gov/projects/qen/Indo2.html).

AlineI, M. (1996-2000): Origini delle lingue d'Europa 1-11, Il Mulino, Bologna.

ALINEI, M. (2001): "Un modello alternativo delle origini dei popoli e delle lingue europee", Le radici prime dell'Europa. Gli intrecci genetici, linguistici, storici, Bruno Mondadori, Milano, pp. 177-208.

AmmerMAn, J. A. (2001): "La transizione neolitica in Europa: oltre l'indigenismo", Le radici prime dell'Europa. Gli intrecci genetici, linguistici, storici, Bruno Mondadori, Milano, pp. 138-160.

Ballester, X. (2002): Las primeras hablas de la humanidad, Valencia.

Cavalli-Sforza, L. L., P. Menozzi and A. Piaza (1994): The History and Geography of Human Genes, Princeton University Press. Princeton.

CHILDE, V. G. (1926): The Aryans. A Study of Indo-European Origins. London.

Devoto, G. (1962): Origini indeuropee, Firenze.

Diamond, J. and P. Bellwood (2003): "Farmers and Their Languages: The First Expansions", Science 300, pp. $597-$ 603.

GAmkrelidze, TH. and V. V. Ivanov (1995): Indo-European and the Indo-Europeans, Berlin - New York.

GimbutAS, M. (1970): "Proto-Indo-European culture: the Kurgan culture during the 5 th to the 3 rd millennia B.C.", Indo-European and Indo-Europeans, (G. Cardona, II. M. Hoenigswald and A. Senn eds.), Philadelphia, pp. 155-198.

Gimbltas, M. (1973a): "Old Europe c. 7000-3500 B.C., the earliest European cultures before the infiltration of the IndoEuropean peoples", JIES 1, pp. 1-20. 
GimbutAS, M. (1973b): "The beginning of the bronze age in Europe and the Indo-Europeans 3500-2500 B.C.", JIES 1. pp. 163-214.

GimbutAs, M. (1977): "The first wave of Eurasian steppe pastoralists into Copper Age Europe", JIES 5, pp. 277-338.

GimButAS, M. (1979): "The three waves of the Kurgan people into Old Europe", Archives suisses d'anthropologie générale 43. pp. 113-117.

GIMBUTAS, M. (1980): "The Kurgan wave migration (c. 3400-3200 B.C.) into Europe and the following transformation of culture", Journal of Near Eastern Studies 8, pp. 273-315.

Gimbutas, M. (1982): "Old Europe in the 5th Millennium B.C.: The European Situation on the Arrival of the IndoEuropeans". The Indo-Europeans in the th and 3th Millennia (E. Polomé, ed.), Ann Arbor, pp. 1-60.

Gimbutas, M. (1989): The Language of the Goddess, San Francisco.

GimbutAs, M. (1990a): "The social structure of Old Europe", JIES 18 , pp. $197-214$

Gimbutas, M. (1990b): "The collision of two ideologies", When tWorlds collide. Indo-Europeans and Pre-Indo-Europeans (T. L. Markey and J. A. Greppin eds.), Ann Arbor, pp. 171-178.

KossinnA, G. (1902): "Die Indogermanische Frage archälogisch beantwortet", Zeitschrift für Ethnologie 34, pp. 161-222.

Lehmann, W. P. (2002): Pre-Indo-European, Journal of Indo-European Studies Monograph 14, Washington.

MeIL.LT, A. (1950): Les dialectes indo-européens, Paris.

OTTE, M. (1995): "Diffusion des langues modernes en Eurasie prehistorique", C.R. Acad. Sci. Paris, 31, série II ${ }^{a}$.

OTTE, M. (1997): "The Diffusion of Modern Languages in Prehistoric Eurasia", Archaeology and Language I (R. Blench and M. Spriggs eds.), Routledge, London and New York, pp. 74-81.

PENKA, K. (1883): Origines ariacae, Vienna.

Penka, K. (1886): Die Herkunft der Arier, Wien.

POESCHE, TH. (1878): Die Arier. Ein Beitrag zur historischen Anthropologie, Jena. 
PoKorny, J. (1959): Indogermanisches Etymologisches Wörterbuch, München.

Renfrew, C. (1987): Archeology and Language: The Puzzle of Indo-European Origins, Cambridge - New York.

ReNFrew, C. (1992): "World Languages and Human Dispersal: A Minimalist View", Transition to Modernity: Essays on Power, Wealth and Belief (J. M. Hall and I. C. Jarvie eds.) Cambridge University Press, Cambridge, pp. 11-68.

Renfrew, C. (1996): "Language Families and the Spread of Farming", The Origins and Spread of Agriculture and Pastoralism in Eurasia (D. R. Harris ed.), UCL Press, London, pp. 70-92.

Renfrew, C. (1998): "The Origin of World Linguistic Diversity: An Archaeological Perspective", The Origin and Diversification of Languages (N. G. Jablonski and L. C. Aiello eds.), California Academy of Sciences, San Francisco, pp. 171-192.

RENEREW, C. (2001): "Origini indoeuropee: verso una sintesi”, Le radici prime dell'Europa. Gli intrecci genetici, linguistici, storici. Bruno Mondadori, Milano, pp. 116-137.

Schlerath, B. (1973): Die Indogermanen: Das Problem der Expansion eines Volkes im Lichte seiner sozialen Struktur, Innsbruck.

SCHLerath, B. (1981): "Ist ein Raum/Zeit-Modell für eine rekonstruierte Sprache möglich?", KZ 95, pp. 175-202.

SCнміDT, J. (1872): Die Verwandtschaftsverhältnisse der indogermanischen Sprachen, Weimar.

SCHMidT, K. H. (1991): "Latin and Celtic: Genetic Relationship and Areal Contacts", BBCS 38, pp. 1-19.

VAN ANDEL, T. H. and P. C. TZEDAKIS (1996): "Palaeolithic landscapes of Europe and environs: 150,000-25,000 years ago: an overview", Quaternary Science Reviews 15, pp. 481-500.

ZIMMER, S. (1990): Ursprache, Urvolk und Indogermanisierung: zur Methode der indogermanischen Altertumskunde, Institut für Sprachwissenschaft der Universităt Innsbruck, Innsbruck. 